\title{
Pembuatan Aplikasi Filling Rekam Medis Rumah Sakit
}

\author{
Sustin Farlinda ${ }^{1 *}$, Rinda Nurul ${ }^{1}$, Sapitri Adinta Rahmadani ${ }^{1}$ \\ ${ }^{1}$ Rekam Medik Jurusan Kesehatan, Politeknik Negeri Jember \\ Email: sustin@polije.ac.id*
}

\begin{abstract}
Abstrak
Sistem informasi rekam medis sub bagian filling adalah informasi yang dihasilkan secara terkomputerisasi yang juga dapat digunakan untuk mempermudah petugas rekam medis di unit filling dalam pencarian dokumen rekam medis yang sedang dipinjam dan mempermudah dalam pelaksanaan retensi dengan studi kasus pada RSIA Srikandi IBI Jember. Filling adalah unit kerja rekam medis yang diakreditasi oleh Departemen Kesehatan yang berfungsi sebagai tempat pengaturan dan penyimpanan dokumen atas dasar sistem penataan tertentu melalui prosedur yang sistematis, sehingga sewaktu-waktu dibutuhkan dapat menyajikan secara cepat dan tepat. Pada sistem penyimpanan (filling) menggunakan Sentralisasi dengan penomoran Terminal Digit Filling, dengan jumlah rata-rata pasien rawat jalan 45-50 pasien dan rawat inap 10-15 pasien.Peneliti menggunakan jenis penelitian kualitatif yaitu untuk pengumpulan data dengan cara wawancara, observasi, FGD, serta dokumentasi dan menggunakan metode waterfall. Dalam proses perancangan sistem ini menggunakan Flowchart system, Contex Diagram, Data Flow Diagram, Entity Relationship Diagram serta dalam mengimplementasikan program menggunakan microsoft visual basic 6.0.Hasil dari penelitian ini adalah sistem informasi rekam medis filling untuk mempermudah petugas dalam mengontrol DRM di filling melalui peminjaman, pengembalian serta retensi. Peneliti selanjutnya diharapkan dapat mengintegrasikan pada SIMRS yang ada agar pengisian data rekam medis dapat secara otomatis muncul ketika di bagian filling.
\end{abstract}

Kata kunci : Rekam Medis Filling, Waterfall, Contex Diagram ,Microsoft Visual Basic 6.0,

\section{Pendahuluan}

Rumah sakit adalah institusi pelayanan kesehatan yang menyelenggarakan pelayanan kesehatan perorangan secara paripurna yang menyediakan pelayanan rawat inap, rawat jalan, dan gawat darurat. Rumah Sakit diselenggarakan berasaskan Pancasila dan didasarkan kepada nilai kemanusiaan, etika dan profesionalitas, manfaat, keadilan, persamaan hak dan anti diskriminasi, pemerataan, perlindungan dan keselamatan pasien, serta mempunyai fungsi sosial. Salah satu mutu pelayanan yang harus dijaga di rumah sakit adalah adanya penyelenggaraan rekam medis menurut UU no.44 tahun 2009.

Berdasarkan Permenkes RI No. 269 tahun 2008 yang dimaksud dengan rekam medis adalah berkas yang berisikan catatan dan dokumen tentang identitas pasien, pemeriksaan, pengobatan, tindakan, dan pelayanan lain yang telah diberikan kepada pasien. Catatan-catatan tersebut sangat penting untuk pelayanan pasien karena dengan data yang lengkap dapat memberikan informasi dalam menentukan keputusan baik pengobatan, penanganan, tindakan medis dan lainnya.

Penyelenggaraan proses kegiatan yang dimulai pada saat diterimanya pasien di rumah sakit, dilanjutkan dengan kegiatan pencatatan data medis pasien selama pasien itu mendapatkan pelayanan medis di rumah sakit. Penanganan berkas rekam medik meliputi penyelenggaraan penyimpanan serta pengeluaran berkas dari penyimpanan untuk melayani permintaan atau peminjaman dan untuk keperluan lainnya.

Sistem informasi adalah suatu sistem didalam suatu organisasi yang mempertemukan kebutuhan pengolahan transaksi harian, mendukung operasi, bersifat manajerial dan kegiatan strategi dari suatu dan menyediakan pihak luar tertentu dengan laporan-laporan yang diperlukan. Sistem informasi juga dapat digunakan untuk mempermudah petugas rekam medis di sub bagian filling dalam pencarian dokumen rekam medis untuk kunjungan pasien baru dan kunjungan pasien lama.

Filling adalah unit kerja rekam medis yang diakreditasi oleh Departemen Kesehatan yang berfungsi sebagai tempat 
pengaturan dan penyimpanan dokumen atas dasar sistem penataan tertentu melalui prosedur yang sistematis, sehingga sewaktuwaktu dibutuhkan dapat menyajikan secara cepat dan tepat. Pada bagian filling sering terjadi masalah seperti missfile serta mengakibatkan keterlambatan pencarian dokumen rekam medis, satu pasien mempunyai dua nomor rekam medis, angka pada dokumen rekam medis yang tidak jelas.

Berdasarkan hasil survei pendahuluan yang telah dilakukan di Rumah Sakit Ibu dan Anak Srikandi IBI Jember. Pada sistem penyimpanan (filling) di RSIA Srikandi IBI Jember menggunakan Sentralisasi dengan penomoran Terminal Digit Filling, dengan jumlah rata-rata pasien rawat jalan 45-50 pasien dan rawat inap 10-15 pasien. Salah satu masalah yang terjadi yaitu pada sistem penyimpanan, terjadinya missfile (salah letak atau hilang). Jika rumah sakit mengadakan Imunisasi pasien yang datang mengalami peningkatan, sehingga pada saat pengembalian dokumen rekam medis sering salah letak. Petugas filling hanya berjumlah 2 orang dan mengalami kesulitan karena rak yang masih belum sesuai, dengan susunan satu sap digunakan tiga nomor angka yang berbeda. Dokumen yang dipinjam untuk kepentingan pelayanan kesehatan pada pasien, mengakibatkan petugas filling mengalami kesulitan untuk mengotrol dimana dokumen dipinjam. Dalam sistem peminjaman dan pengembalian dokumen rekam medis pada rak filling petugas masih menggunakan sistem manual yaitu dengan menuliskan pada buku ekspedisi serta mencari dengan membuka satu persatu setiap halaman buku tersebut. Pada unit filling RSIA Srikandi IBI Jember pada tanggal 25 juli sampai dengan 30 juli 2016 pasien yang datang sejumlah 131 pasien, dengan kasus missfile sebanyak 6 dokumen rekam medis. Tingginya angka kejadian missfile pada sistem penyimpanan mengakibatkan sistem pelayanan pada pasien terhambat. Masalah missfile pasien yang seharunya mendapatkan pelayanan secara cepat, namun harus menunggu lama karena dokumen pasien tersebut tidak ada pada rak penyimpanan. Hal tersebut dapat mengakibatkan pasien yang merasa kecewa kemudian berdampak pada tingkat kepuasan pasien terhadap pelayanan rumah sakit. Sistem informasi pada era sekarang sangat dibutuhkan, karena dapat berfungsi mempermudah petugas filling untuk mengontrol atau mengendalikan dokumen rekam medis yang dipinjam sudah dikembalikan atau belum. Petugas tidak akan memerlukan waktu yang lama untuk pengecekkan dimana dokumen rekam medis sebelumnya dipinjam, petugas dapat langsung mencari dengan mengetikan nomor rekam medis pada sistem informasi. Dengan begitu dokter tidak perlu menunggu lama untuk melakukan pemeriksaan pada pasien, jika petugas dengan cepat dapat mengetahui bahwa dokumen pasien belum kembali pada ruang penyimpanan namun ada pada poliklinik atau dipinjam dokter di waktu sebelumnya. Dengan adanya sistem informasi rekam medis unit filling di rumah sakit Ibu dan Anak Srikandi IBI Jember, dapat mempermudah petugas filling bukan hanya dapat mengontrol dokumen rekam medis. Namun, petugas juga dapat dengan mudah mengetahui bahwa dokumen termasuk dokumen rekam medis aktif atau inaktif (retensi) secara komputerisasi. berdasarkan latar belakang tersebut, peneliti mengambil judul "Perancangan Sistem Informasi Rekam Medis Sub Bagian Filling Di RSIA Srikandi IBI Jember Tahun 2016".

\section{Metode penelitian}

Penelitian dilakukan di Rumah Sakit Ibu Dan Anak Srikandi IBI Jember yang beralamat di jalan KH. Agus Salim no.20 Jember. Jenis penelitian ini adalah penelitian kualitatif dengan metode waterfall. Data yang diperoleh hasil dari observasi, wawancara, FGD pada petugas rekam medis sub bagian filling.

\section{Hasil dan pembahasan}

\subsection{Analisi Kebutuhan Sistem Perangkat lunak}

Dalam observasi peneliti melakukan wawancara kepada petugas filling yang 
berjumlah dua orang kemudian dan melakukan FGD dengan jumlah anggota minimal lima orang sehingga peneliti memperoleh hasil kebutuhan item - item apa saja yang diperlukan rekam medis filling. Berdasarkan hasil wawancara dan FGD (Focus Group Discussion) pada petugas filling mengenai kebutuhan dan harapan dikemudian hari, agar adanya sistem yang terkomputerisasi yang dapat mempermudah untuk mengontrol dokumen rekam medis yang dipinjam dan pada saat pengembalian serta mempermudah dalam pelaksanaan retensi. Hasilnya sebagai berikut:

Alasan responden pada wawancara yang dilakukan oleh peneliti kenapa perlu adanya system informasi rekam medis sub bagian filling yaitu:

"karena Buku ekspedisi yang kurang efektif dari semua berkas masih belum bisa diketahui DRM yang belum kembali ke unit RM Di URM RSIA serta petugas tidak memiliki buku ekspedisi peminjaman hanya memiliki buku ekspedisi pengembalian dimana terkadang lupa dicatat pada buku ekspedisi jika petugas RM tidak ada, karena agar untuk mengontrol dokumen rekam medis yang dalam masa retensi dan bisa menjadi remaider masa retensi dukomen rekam medis" (R1R2)

Item yang dibutuhkan proses wawancara sebelum proses buat perancangan dan FGD setelah sistem informasi selesai pada sistem informasi rekam medis sub bagian filling yaitu:

\begin{tabular}{|l|}
\hline "Item yang dibutuhkan pada \\
perancangan sistem informasi yaitu No.RM, \\
Nama, Tanggal Masuk, Tanggal Akhir \\
Berkunjung (kunjungan Terakhir), Diagnosa \\
Akhir, Jenis Tindakan. Sedangkan pada saat \\
pengujian sistem informasi perlu ditambahi \\
hak akses \\
(R1 R2)
\end{tabular}

Berdasarkan hasil wawancara dan FGD dia atas bahwa petugas sulit mengotrol DRM yang dipinjam dan memerlukan sistem informasi yang di dalam nya terdapat nama, nomor RM, tamggal masuk, tanggal keluar, Diagnosa akhir, serta tindakan jika ada agar mempermudah saat pelaksanaan retensi. KEPMENKES 269 tahun 2008 tentang penyimpanan, pemusnahan menjelaskan bahwa batas waktu dilakukan pemusnahan dan item - item apa saja yang harus masih tetap disimpan tidak dimusnahkan.

\subsection{Merancang Sistem Menggunakan Folwchart system, Context Diagram (CD), DFD, ERD}

Hasil rancangan sistem berupa flowchart system, context diagram, DFD, dan ERD.

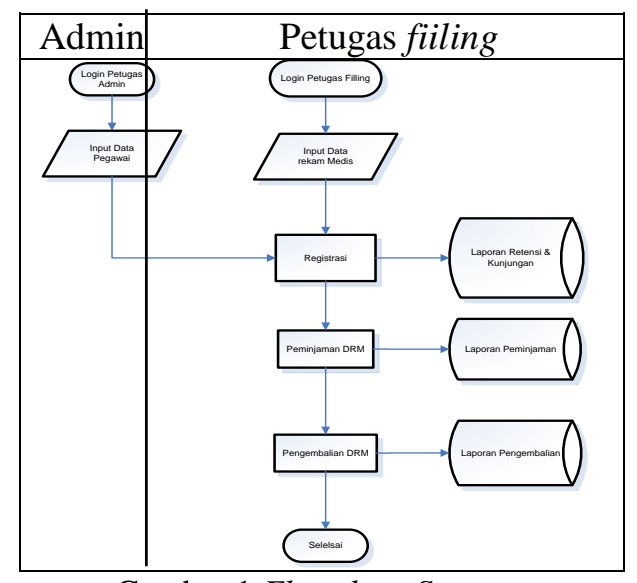

Gambar 1 Flowchart System

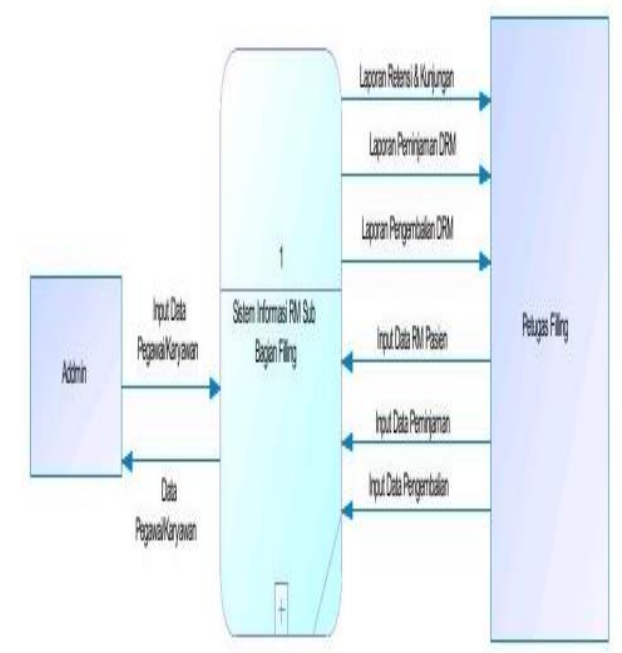

Gambar 2 Context diagram 
ISSN : 2354-5852

e-ISSN : 2579-5783

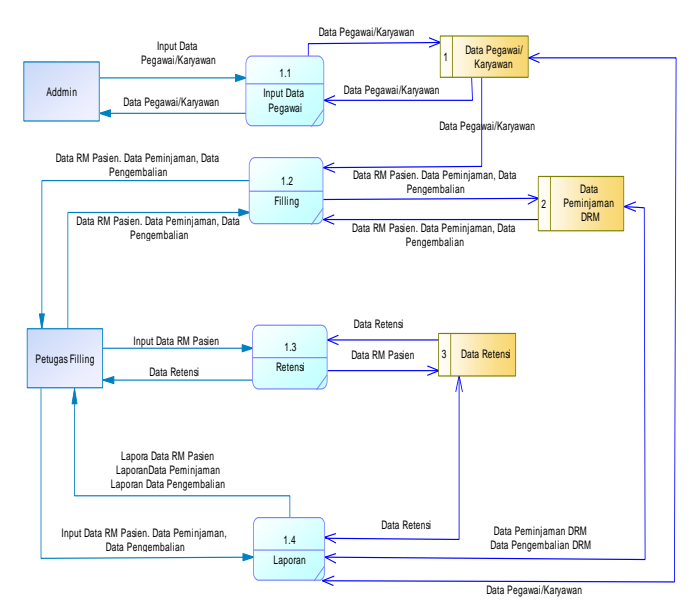

Gambar 3 DFD level 1

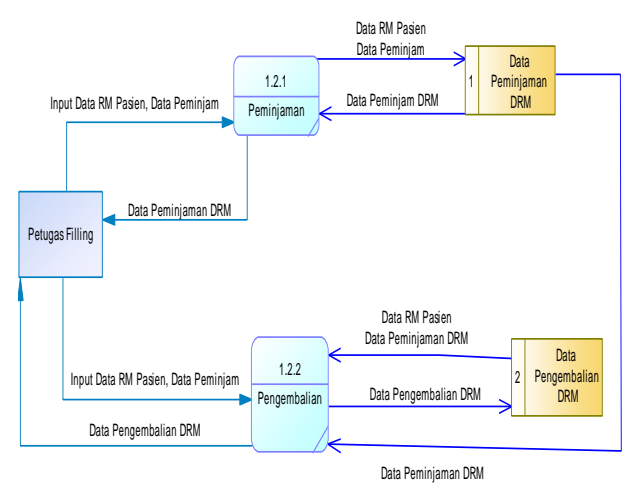

Gambar 4 DFD Level 2 Proses Filling

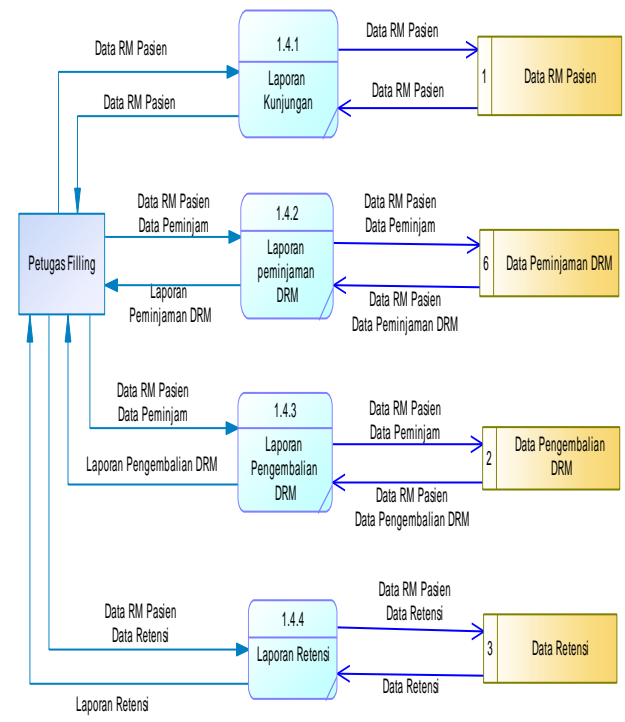

Gambar 5 DFD level 2 proses Laporan

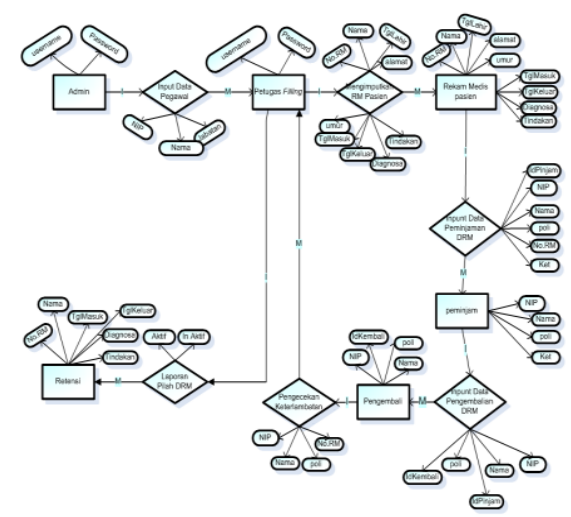

Gambar 6 Entity Relationship Diagram (ERD)

\subsection{Merancang Sistem Menggunakan Aplikasi Visual Basic 6.0 Dan Basis Data Menggunakan Microsoft Access}

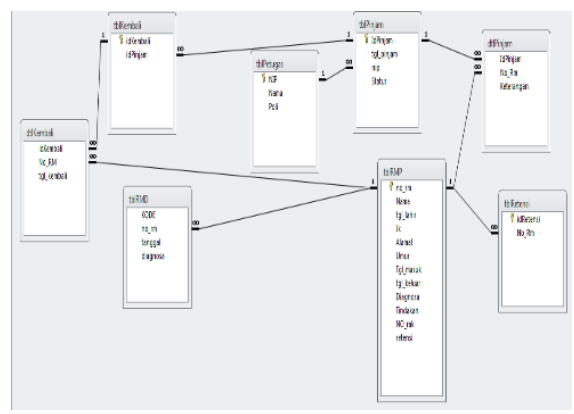

Gambar 7 Basis Data

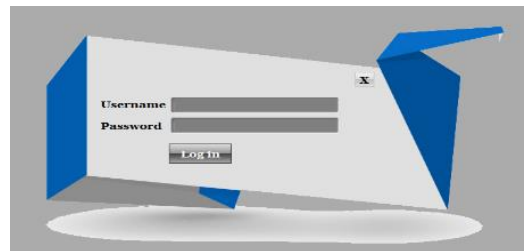

Gambar 8 Form Login

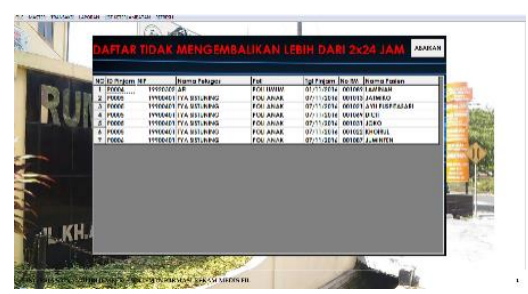

Gambar 9 Form Menu 


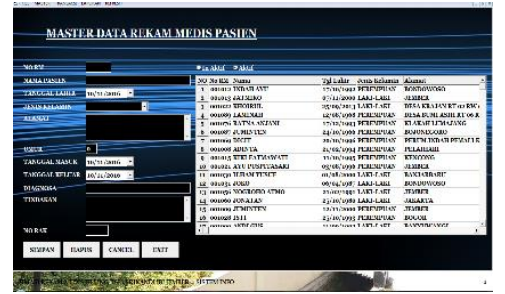

Gambar 10 Form Pasien

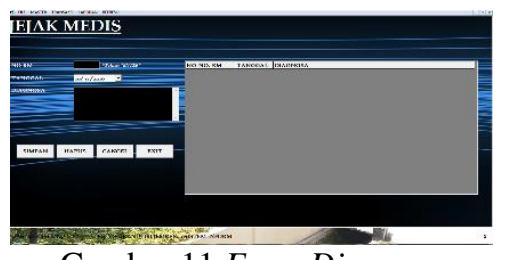

Gambar 11 Form Diagnosa

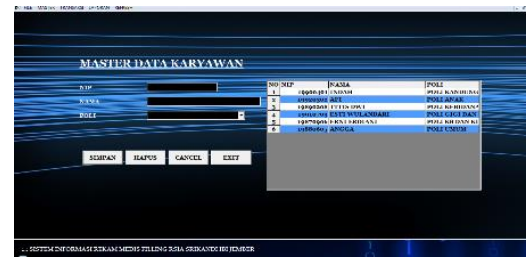

Gambar 12 Form Pegawai

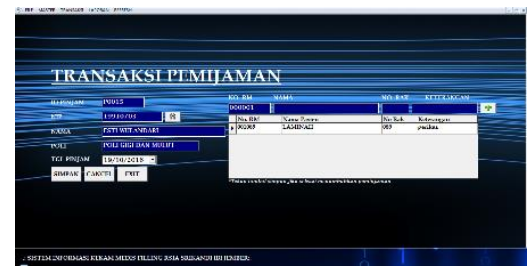

Gambar 13 Form Peminjaman

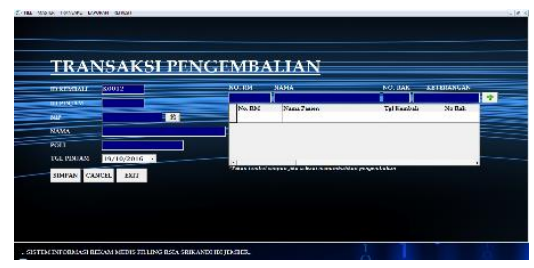

Gambar 14 Form Pengembalian

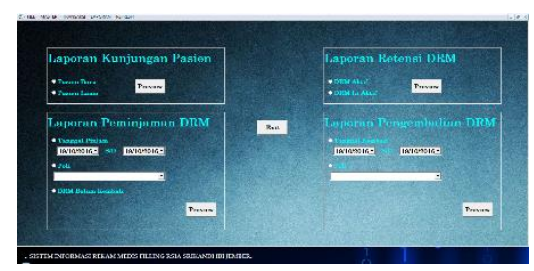

Gambar 15 Form Laporan
Pengembalian, Form Laporan, Form Refresh, Form File (Logout dan Exit).

\section{Kesimpulan}

Kebutuhan yang di perlukan petugas filling dalam pembuatan sistem informasi adalah nama, nomor RM, tanggal masuk, tanggal keluar, Diagnosa akhir, serta tindakan jika ada agar mempermudah saat pelaksanaan retensi.

Mendesain sistem informasi rekam medis filling di RSIA Srikandi IBI Jember, desai sistem informasi menggunakan microsoft visio 2003 untuk pembuatan ( flowchart system, Entity Relationship Diagram), menggunakan power designer 15.2 untuk pembuatan contex diagram dan data flow diagram (DFD), serta menggunakan microsoft access untuk membuat database.

Mentranslasikan kode program sesuai dengan desain yang telah dibuat pada perancangan sistem informasi rekam medis filling di RSIA Srikandi IBI Jember, dimana aplikasi ini dibuat dengan menggunakan Visual Basic 6.0 sehingga coding yang digunakan sesuai bahasa pemrograman tersebut.

Pengujian sistem informasi rekam medis filling ini di ujikan pada dua orang petugas filling yang ada di RSIA Srikandi IBI Jember, dengan tujuan yang diharapakan semua form dapat di uji dan berhasil.

Sebanyaiknya RSIA Srikandi IBI Jember dapat mengganti buku ekspedisi dengan sistem komputerisasi agar petugas filling dapat mengontrol dokumen rekam medis yang dipinjam dan mengurangi dampak terjadinya missfile. Agar petugas yang akan melakukan pelaksanaan retensi bisa lebih mudah jika pengecekan dilakukan secara komputerisasi. Peneliti selanjutnya diharap dapat mengintegrasikan pada SIMRS yang ada agar pengisian data rekam medis dapat secara otomatis muncul ketika di bagian filling.

\section{Daftar pustaka}

Budi, Savitri Citra. 2011. Manajemen Unit Kerja Rekam Medis. Yogyakarta; Quantum Sinergis Media. 
Djaelani, Aunu R. 2013. Teknik Pengumpulan Data Dalam Penelitian Kualitatif. Semarang:FPTK IKIP Veteran Semarang.

Departemen Kesehatan RI. 2006. Pedoman Penyelenggaraan Rekam Medis Rumah Sakit di Indonesia. Jakarta. http://www.scribd.com. [diakses 18 Maret 2016].

Hatta, Gemala.2012. Pedoman Manajemen Informasi Kesehatan Disarana Pelayanan Kesehatan.Edisi Revisi 2. Jakarta:Penerbit Universitas Indonesia.

Huffman, Edna K. 1999. Health Information Management. Berwyn, Illionis: Physicians Record Company.

Kurniawan, Moch. Arif. 2015. Perancanagan Dan Pembuatan Sistem Informasi peminjaman dan pengembalian Rekam Medis Di Rumah Sakit Daerah dr. Soebandi Jember. Skripsi, Jember:Program Studi D-IV Reklam Medik Politeknik Negeri Jember.

Kurniawati. A \& Asfawa. S. 2015.Analisis Deskriptif Faktor Penyebab Kejadian Missfile Di Bagian Filling Rawat Jalan Rsud Dr. M. Ashari Pemalang Tahun 2015.Semarang: UDINUS.

Mudiono, D.R.P. 2015. Perancanagan Dan Pembuatan Sistem Informasi Pengendalian Berkas Rekam Medis Di Rumah Sakit Kalisat Jember. Skripsi, Jember:Program Studi DIV Reklam Medik Politeknik Negeri Jember.

Notoatmodjo, S. 2010. Metodologi Penelitian Kesehatan. Jakarta: Rineka cipta.

Nurullah. 2012. Perancangan Dan Pembuatan Sistem Informasi Akuntansi Pada STMIK
U'BUDIYAH menggunakan

VB.NET.

http://ejournal.uui.ac.id.Diakses

Pada Juli 2016

$$
\begin{aligned}
& \text { Permenkes RI.2010. No. } \\
& \text { 340/Menkes/Per/III/2010 tentang } \\
& \text { kalsifikasi rumah sakit. } \\
& \text { http://bppsdmk.depkes.go.id/we } \\
& \text { b/filesa/peraturan/2.pdf. diakses } \\
& 22 \text { juni } 2015 .
\end{aligned}
$$

Sukamto, Sulistyo.W, Suyanto.B. 2012.Sistem Terpadu Rekam Medik Rumah Sakit Dengan Smart Card. Semarang:Program Studi Teknik Informatika Politeknik Negeri Semarang. Jurnal Informatika.

Suyantara I.G.N. 2015.Merancang Aplikasi Rekam Medis dengan VB.Net. Jakarta: Penerbit PT Elex Medika Komputindo. 